\title{
Analysis of the Effects of Day-Time vs. Night-Time Surgery on Renal Transplant Patient Outcomes
}

\author{
Nesrin Sugünes ${ }^{1}$, Anna Bichmann ${ }^{2}$, Nadine Biernath ${ }^{1}$, Robert Peters ${ }^{1}$, Klemens Budde ${ }^{3}$, \\ Lutz Liefeldt ${ }^{3}$, Thorsten Schlomm ${ }^{1}$ and Frank Friedersdorff ${ }^{1, *}$ \\ 1 Department of Urology, Charité-Universitätsmedizin Berlin, Corporate Member of Freie Universität Berlin, \\ Humboldt-Universität zu Berlin, and Berlin Institute of Health, Charitéplatz 1, 10117 Berlin, Germany \\ 2 Department of Anesthesiology and Operative Intensive Care Medicine, Charité-Universitätsmedizin Berlin, \\ Corporate Member of Freie Universität Berlin, Humboldt-Universität zu Berlin, and Berlin Institute of \\ Health, Charitéplatz 1, 10117 Berlin, Germany \\ 3 Department of Nephrology, Charité-Universitätsmedizin Berlin, Corporate Member of Freie Universität \\ Berlin, Humboldt-Universität zu Berlin, and Berlin Institute of Health, 10117 Berlin, Germany \\ * Correspondence: frank.friedersdorff@charite.de
}

Received: 30 June 2019; Accepted: 12 July 2019; Published: 18 July 2019

\begin{abstract}
Sleep deprivation and disruption of the circadian rhythms could impair individual surgical performance and decision making. For this purpose, this study identified potential confounding factors on surgical renal transplant patient outcomes during day and night. Our retrospective cohort study of 215 adult renal cadaver transplant recipients, of which 132 recipients were allocated in the "day-time" group and 83 recipients in the "night-time" group, primarily stratified the patients into two cohorts, depending on the start time. Within a $24 \mathrm{~h}$ operational system, "day-time" was considered as being from 8 a.m. to 8 p.m. and "night-time" from 8 p.m. to 8 a.m.. Primary outcomes examined patient and graft survival after three months and one year. Secondary outcomes included the presence of acute rejection (AR) and delayed graft function (DGF), as well as the rate of postoperative complications. In log-rank testing, "day-time" surgery was associated with a significantly higher risk of patient death $(p=0.003)$, whereas long-term graft survival was unaffected by the operative time of day. The mean cold ischemia time (CIT), which was $12.4 \pm 5.3 \mathrm{~h}$ in the "night-time" group, was significantly longer compared to $10.7 \pm 3.6$ for those during the day $(p=0.01)$. We observed that "night-time" kidney recipients experienced more wound complications. From our single-centre data, we conclude that night-time kidney transplantation does not increase the risk of adverse events or predispose the patient to a worse outcome. Nevertheless, further research is required to explore the effect of fatigue on nocturnal surgical performance.
\end{abstract}

Keywords: night-time renal transplantation; graft survival; patient survival/outcome; surgical complications

\section{Introduction}

Kidney transplant outcomes have improved in recent years through novel technical approaches and immunosuppressive therapy [1-4]. There is still a deleterious impact of surgical complications on graft and patient survival $[5,6]$. Several risk factors of surgical complications have been identified, including donor and recipient characteristics, organ recovery and surgical implantation techniques [7]. Recipients with a prolonged cold ischemia time (CIT) have a greater risk for delayed graft function (DGF) and diminished long-term allograft survival [8]. To reduce CIT, surgery is initiated at any time of the day to preserve the organ quality. Further risk factors which are detrimental for patient outcome are human factors, including physical and mental fatigue and sleep deprivation, which are known to 
affect communication, attention and situational awareness, as well as psychomotor function $[9,10]$. It has been hypothesized that sleep deprivation reduces the performance of surgeons by affecting cognitive and fine motor skills [11,12]. In a technically demanding field, such as renal transplantation, meticulous preparation and excellent suturing techniques are required to prevent vascular and urologic complications [7]. The impact of physician fatigue on the medical error rate and clinical outcomes has been actively researched [13-15]. A number of studies demonstrated that operative outcomes were not related to sleep deprivation [16-18], whereas others link mental fatigue to surgical complication rates after general procedures [19]; and mortality after liver transplants [20]. To our knowledge, the literature regarding the impact of night-time surgery on outcomes after kidney transplantation is underrepresented and recent studies have reported conflicting results [21-24]. For this purpose, we conducted a retrospective cohort study to examine the association between the time of day of transplantation surgery (night-time vs. day-time) on surgical renal transplant patient outcomes. The primary outcomes examined were patient and graft survival after three months and one year. Secondary outcomes included the presence of acute rejection (AR) and DGF and other postoperative complications. We hypothesize, that renal transplantation surgery performed during the night-time would have inferior outcomes compared to those performed during the day.

\section{Methods}

We performed a retrospective cohort study of all adult patients undergoing cadaver renal transplantation at Charité University Hospital Campus Mitte, between 01.01.2011 and 31.12.14. Data on kidney transplantation and operative variables, as well as follow-up data, were obtained retrospectively from internal SAP (System, Anwendung, Produkte) and national TBase (Kidney Transplant Information System) electronic databases. The entire analysis was in adherence with correct scientific research work terms of the Charité Medical University of Berlin including full anonymization of patient data ('Good Scientific Practice', version 29/03/18).

\subsection{Study Population}

Transplants were stratified by the operative time of day. "Day-time" surgery was defined as surgery that started between 8:00 a.m. and 8:00 p.m. and "night-time" surgery was defined as surgery that started between 8:00 p.m. and 8:00 a.m. Twelve surgeons performed all the transplantations using standard surgical techniques. Kidneys were placed either in the right or left iliac fossa via an extraperitoneal approach. The renal graft vessels were anastomosed end-to-side to the recipient external or common iliac vessels. In all cases, except for one patient with urinary diversions (ileal conduit), a standard Lich-Gregoir ureteroneocystostomy was performed. A double-J ureteral stent was systematically inserted and removed six weeks later, followed by a urethral catheter for ten days postoperatively. All recipients received intravenous prophylactic antibiotics at the time of transplant. Graft function was monitored by Doppler ultrasound scanning, serum creatinine level and urine output measurements. The routine immunosuppression protocol that was initiated consisted of a triple regimen, including calcineurin inhibitors or a mammalian target of rapamycin inhibitors, mycophenolate mofetil (MMF), and steroids.

\subsection{Data Collection}

Patient and donor demographics and clinical data were collected by chart review. The parameters evaluated in this study were, recipient characteristics of age, gender, body mass index (BMI), comorbidities (hypertension, diabetes mellitus, cardiovascular disease, stroke and peripheral vascular disease), previous abdominal surgery, causation of end-stage renal disease, previous transplantation, duration of pre-transplant dialysis, and human leukocyte antigen (HLA) mismatches. The donor features were age, gender, BMI, site of donor kidney, number of graft arteries and the presence of graft vessels atherosclerosis. Perioperative factors included the surgeon's experience (consultant, resident), cold and warm ischemia time (WIT), and incidence of intraoperative complications. CIT was defined 
as the time between the start of cold perfusion and removal of the renal allograft from ice. Warm ischemia time was defined as the time between the placement of the renal allograft into the iliac fossa of the recipient until revascularization of the kidney occurred.

\subsection{Outcome Measures}

The primary outcomes examined were patient and graft survival after three months and one year, respectively. Secondary outcomes included the presence of AR and DGF, as well as the rate of postoperative complications. Postoperative complications were examined for the first three months after surgery and defined according to the Clavien-Dindo classification system [20].

\subsection{Statistical Analysis}

Univariate comparisons were performed using the Chi-Square test or Fisher exact test for categorical variables. Continuous variables were tested with the non-paired Student $t$-test and the Mann-Whitney-U test for data with non-normal distribution. Categorical variables were displayed as $\mathrm{n}(\%)$ and continuous variables mean \pm standard deviation (SD); and nonparametric distribution as median (minimum-maximum). Patient and allograft survival rates were estimated using the Kaplan-Meier method and comparisons of survival rates were performed using the log-rank test. For all statistical measures, a $p$-value below 0.05 was considered statistically significant. Statistical analyses were performed using SPSS software (SPSS Inc., version 25, Armonk, NY, USA).

\section{Results}

The baseline characteristics and operative parameters in the two groups stratified according to the time surgery was performed are presented in Table 1 . The two groups were similar with respect to most of the baseline characteristics, except for the higher distribution of male donors for the "day-time" group ( $p=0.05$ ). The mean CIT was $12.4 \pm 5.3 \mathrm{~h}$ in the "night-time" group compared with $10.7 \pm 3.6$ for the "day-time" cohort $(p=0.01)$. The total operative time from skin incision to wound closure was similar in kidney transplants performed at all times. Considering the surgical expertise, $76.5 \%$ of "day-time" procedures were performed by a consultant compared to $72.3 \%$ during the "night-time" $(p=0.49)$. A total of six intraoperative surgical complications occurred in the overall cohort of 215 recipients $(2.8 \%)$ : renal artery stenosis $(n=2)$, renal vein injury $(n=2)$, renal vein thrombosis $(n=1)$ and iatrogenic bladder perforation $(n=1)$, which were immediately treated. The difference in incidence of intraoperative surgical complication was statistically insignificant with $3.8 \%(n=5)$ during the day and $1.2 \%(n=1)$ during the night $(p=0.34)$. We observed a higher incidence of DGF nocturnal operations with $54.2 \%$ compared to $47.7 \%$ in the "day-time" group $(p=0.35)$. The incidence of AR was $25 \%$ for "night-time" compared to $22 \%$ for "day-time" allograft recipients ( $p=0.57)$. Table 2 shows patient outcomes.

Table 1. Recipient and donor characteristics and operative details. Results are presented as mean and standard deviations or as absolute and relative frequencies; $\mathrm{h}$ —hours; min-minutes; ESRD—end-stage renal disease; * statistically significant.

\begin{tabular}{ccccc}
\hline Donor Characteristics & All $(\boldsymbol{n}=\mathbf{2 1 5})$ & $\begin{array}{c}\mathbf{8 : 0 0} \text { a.m.-8:00 p.m. } \\
(\boldsymbol{n}=\mathbf{1 3 2})\end{array}$ & $\begin{array}{c}\mathbf{8 : 0 0} \text { p.m.-8:00 a.m. } \\
(\boldsymbol{n}=\mathbf{8 3})\end{array}$ & $p$-Value \\
\hline Age (years) & $54.2 \pm 14.8$ & $55.2 \pm 15.1$ & $52.5 \pm 14.3$ & 0.19 \\
Male gender & $114(53.0 \%)$ & $77(58.3 \%)$ & $37(44.6 \%)$ & 0.05 \\
BMI (kg/m $\left.{ }^{2}\right)$ & $25.8 \pm 4.4$ & $25.8 \pm 4.2$ & $25.8 \pm 4.8$ & 0.88 \\
Right kidney side & $107(49.8 \%)$ & $66(50.0 \%)$ & $41(49.4 \%)$ & 0.93 \\
Multiple renal arteries (\%) & $45(20.9 \%)$ & $28(21.2 \%)$ & $17(20.5 \%)$ & 0.90 \\
Atherosclerosis of graft vessels & $128(59.5 \%)$ & $77(58.3 \%)$ & $51(61.4 \%)$ & 0.65 \\
\hline Recipient Characteristics & & & & 0.12 \\
Age (years) & $53.3 \pm 14.7$ & $54.6 \pm 14.6$ & $51.1 \pm 14.7$ & 0.15 \\
Age $>$ 65 years & $64(29.8 \%)$ & $44(33.3 \%)$ & $20(24.1 \%)$ & \\
\hline
\end{tabular}


Table 1. Cont.

\begin{tabular}{|c|c|c|c|c|}
\hline Donor Characteristics & All $(n=215)$ & $\begin{array}{c}\text { 8:00 a.m.-8:00 p.m. } \\
\quad(n=132)\end{array}$ & $\begin{array}{c}\text { 8:00 p.m. }-8: 00 \text { a.m. } \\
(n=83)\end{array}$ & $p$-Value \\
\hline Male gender & $120(55.8 \%)$ & $78(59.1 \%)$ & $42(50.6 \%)$ & 0.22 \\
\hline $\operatorname{BMI}\left(\mathrm{kg} / \mathrm{m}^{2}\right)$ & $25.8 \pm 4.4$ & $26.2 \pm 4.4$ & $25.2 \pm 4.5$ & 0.12 \\
\hline \multicolumn{5}{|l|}{ Cause of ESRD } \\
\hline Glomerulonephritis & $85(39.5 \%)$ & $52(39.4 \%)$ & $33(39.8 \%)$ & \\
\hline Hypertension/renovascular & $41(19.1 \%)$ & $25(18.9 \%)$ & $16(19.3 \%)$ & \\
\hline Polycystic kidney disease & $31(14.4 \%)$ & $20(15.2 \%)$ & $11(13.3 \%)$ & \\
\hline Diabetes mellitus & $16(7.4 \%)$ & $10(7.6 \%)$ & $6(7.2 \%)$ & \\
\hline Interstitial nephritis & $8(3.7 \%)$ & $5(3.8 \%)$ & $3(3.6 \%)$ & \\
\hline System diseases & $8(3.7 \%)$ & $4(3.0 \%)$ & $4(4.8 \%)$ & \\
\hline Reflux nephropathy & $6(2.8 \%)$ & $3(2.3 \%)$ & $3(3.6 \%)$ & \\
\hline Congenital uropathy & $4(1.9 \%)$ & $2(1.5 \%)$ & $2(2.4 \%)$ & \\
\hline Other & $12(5.6 \%)$ & $8(6.1 \%)$ & $4(4.8 \%)$ & \\
\hline Unknown & $4(1.9 \%)$ & $3(2.3 \%)$ & $1(1.2 \%)$ & \\
\hline Re-transplantation & $29(13.5 \%)$ & $17(12.9 \%)$ & $12(14.5 \%)$ & 0.74 \\
\hline Duration on dialysis (days) & $2304 \pm 1155$ & $2331 \pm 1145.5$ & $2261 \pm 1174.6$ & 0.67 \\
\hline Mean HLA-mismatches & $2.5 \pm 1.5$ & $2.5 \pm 1.5$ & $2.5 \pm 1.5$ & 0.95 \\
\hline \multicolumn{5}{|l|}{ Co-Morbidities } \\
\hline Diabetes mellitus & $44(20.5 \%)$ & $29(22.0 \%)$ & $15(18.1 \%)$ & 0.49 \\
\hline Hypertension & $184(85.6 \%)$ & $110(83.3 \%)$ & $74(89.2 \%)$ & 0.24 * \\
\hline $\begin{array}{c}\text { Pre-transplant cardiovascular } \\
\text { disease }\end{array}$ & $47(21.9 \%)$ & $33(25.0 \%)$ & $14(16.9 \%)$ & 0.16 \\
\hline Stroke & $18(8.4 \%)$ & $11(8.3 \%)$ & $7(8.4 \%)$ & 0.98 \\
\hline \multirow{2}{*}{$\begin{array}{l}\text { Peripheral vascular disease } \\
\text { Pre-transplant abdominal } \\
\text { surgery }\end{array}$} & $21(9.8 \%)$ & $7(5.3 \%)$ & $14(16.9 \%)$ & 0.05 \\
\hline & $84(39.1 \%)$ & $56(42.4 \%)$ & $28(33.7 \%)$ & 0.20 \\
\hline \multicolumn{5}{|l|}{ Operation Characteristics } \\
\hline Total operative time (min) & $203 \pm 46.3$ & $203.5 \pm 44.4$ & $202.3 \pm 49.6$ & 0.85 \\
\hline Warm ischemia time (min) & $51.2 \pm 12.3$ & $51.4 \pm 12.1$ & $50.8 \pm 12.6$ & 0.74 \\
\hline Cold ischemia time $(\mathrm{h})$ & $11.4 \pm 4.5$ & $10.7 \pm 3.6$ & $12.4 \pm 5.3$ & 0.01 * \\
\hline Consultant & $161(74.9 \%)$ & $101(76.5 \%)$ & $60(72.3 \%)$ & 0.49 \\
\hline Intraoperative complication & $6(2.8 \%)$ & $5(3.8 \%)$ & $1(1.2 \%)$ & 0.34 \\
\hline
\end{tabular}

Table 2. Graft and recipient outcome, ${ }^{*}$ statistically significant.

\begin{tabular}{|c|c|c|c|c|}
\hline & All $(n=215)$ & $\begin{array}{c}\text { 8:00 a.m. }-8: 00 \text { p.m. } \\
\quad(n=132)\end{array}$ & $\begin{array}{c}\text { 8:00 p.m. }-8: 00 \text { a.m. } \\
(n=83)\end{array}$ & $p$-Value \\
\hline Overall patient survival & & & & 0.017 * \\
\hline At 3 months & $212(98.6 \%)$ & $129(97.7 \%)$ & $83(100 \%)$ & \\
\hline At 1 year & $206(95.8 \%)$ & $123(93.2 \%)$ & $83(100 \%)$ & \\
\hline Death censored graft survival & & & & 0.907 \\
\hline At 3 months & $207(96.3 \%)$ & $126(95.5 \%)$ & $81(97.6 \%)$ & \\
\hline At 1 year & $202(93.9 \%)$ & $123(93.2 \%)$ & $79(95.2 \%)$ & \\
\hline Delayed graft function & $108(50.2 \%)$ & $63(47.7 \%)$ & $45(54.2 \%)$ & 0.350 \\
\hline Acute rejection rate & $50(23.3 \%)$ & $29(22 \%)$ & $21(25.3 \%)$ & 0.570 \\
\hline \multicolumn{5}{|l|}{$\begin{array}{l}\text { Serum creatinine }(\mathrm{mg} / \mathrm{dL}) \text { after } \\
\text { transplantation median (range) }\end{array}$} \\
\hline 1 week $(n=213)$ & $4.4(0.93-14.51)$ & $4.4(0.93-12.99)$ & $4.4(1.06-14.51)$ & 0.730 \\
\hline 4 weeks $(n=212)$ & $1.72(0.68-17.0)$ & $1.74(0.68-17.0)$ & $1.71(0.80-7.16)$ & 0.710 \\
\hline 24 weeks $(n=205)$ & $1.45(0.59-4.42)$ & $1.45(0.59-4.42)$ & $1.45(0.71-3.35)$ & 0.660 \\
\hline 60 weeks $(n=200)$ & $1.38(0.46-4.71)$ & $1.39(0.46-4.71)$ & $1.34(0.67-2.49)$ & 0.270 \\
\hline Follow-up (months) & $49.2 \pm 14.6$ & $47.1 \pm 15.6$ & $52.50 \pm 12.4$ & $0.008 *$ \\
\hline
\end{tabular}

\subsection{Patient and Graft Survival}

The Kaplan-Meier survival curves for patient survival (Figure 1a) and death-censored allograft survival (Figure 1a) by status are shown in Figure 1. In log-rank testing, "day-time" operation was 
associated with a significantly higher risk of patient death (log-rank test 5.65; $p=0.017$ ). During the first 12 months after surgery, a total of nine deaths occurred in the overall sample of 215 kidney transplants recipients $(4.18 \%)$. No death occurred in the "night-time" kidney group within one year of transplantation, whereas two of the 132 "day-time" renal recipients died with a functioning transplant (one case of coronary heart disease, and one of malignancy) and seven patients died after returning to dialysis (all cases due to bacterial sepsis). Kaplan-Meier analyses demonstrated no statistically significant differences for death-censored graft survival (Figure 1b) between the "night-time" and "day-time" recipient cohorts (log-rank test 0.014; $p=0.907$ ).

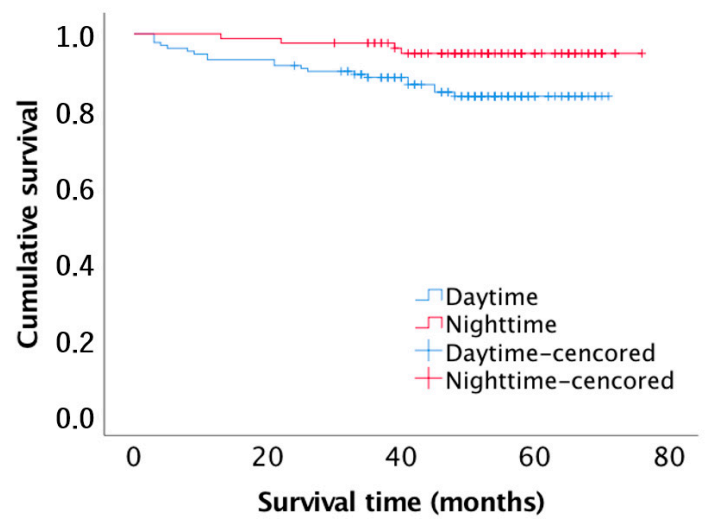

(a)

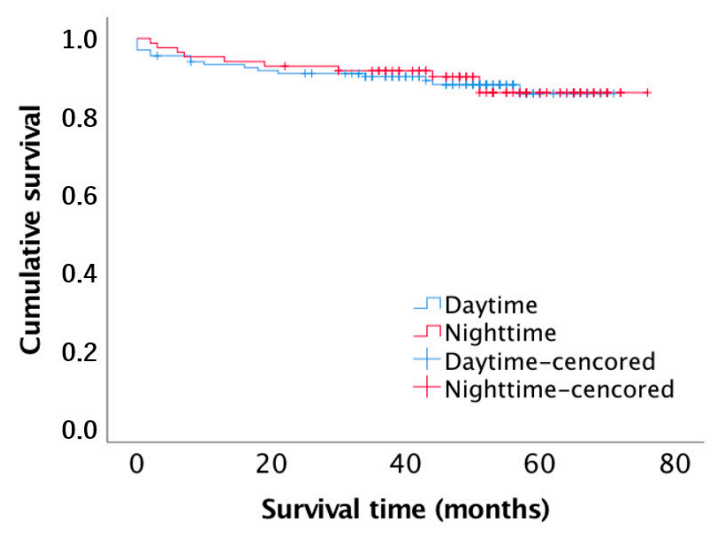

(b)

Figure 1. (a) Kaplan-Meier survival curve for patient survival after "day-time" and "night-time" renal transplantation (log-rank test 5.65; $p=0.017$ ); (b) Kaplan-Meier survival curve for death censored graft survival of patients after "day-time" and "night-time" renal transplantation (log-rank test 0.014; $p=0.907)$.

\subsection{Early Graft Failure}

During the first three months post-operation, graft failure was noticed in seven out of 132 "day-time" allograft recipients (5.3\%), and in two out of $83(2.4 \%)$ "night-time" transplant recipients $(p=0.49)$. In the "day-time" cohort, the most common cause of graft failure was primary non-function $(n=3)$, whereas recurrent disease, sepsis and death with functioning graft were noticed in the other cases, respectively. One "day-time" renal transplant recipient suffered an invasive fungal infection, which produced an allograft vessels aneurysm leading to graft loss. From the "night-time" group, two recipients $(2.4 \%)$ lost the graft during the first three months after transplantation, due to AR and graft infection. 


\subsection{Postoperative Complications}

One or more postoperative complications occurred in 74 out of the 132 "day-time" renal transplant recipients (56\%) compared to 41 of the 83 "night-time" allograft recipients $(49 \%)$ during the first three months post-operation $(p=0.34)$. Each category of complication assessed by the Clavien-Dindo grading system was analysed separately against the two-time groups, of which no category was significantly different (Table 3). In particular, "night-time" and "day-time" renal recipients did not differ significantly in the incidence of postoperative complications requiring medical or surgical reintervention (Clavien-Dindo Grade IIIa/b). Table 4 shows the number of operations that were performed within each time period and the incidence of surgical complications. The most common surgical complications in both groups included haemorrhagic events requiring blood transfusions or surgical intervention $(17.2 \%)$, lymphoceles $(10.7 \%)$, seromas $(9.7 \%)$, and wound dehiscence $(7 \%)$. A statistically insignificant higher incidence of wound complications among "night-time" kidney recipients was observed. The incidence of urologic complications was higher for the "day-time" surgery, which was also statistically insignificant. Among the 12 patients with urological complications, nine $(6.8 \%)$ occurred within the "day-time" group and three $(3.6 \%)$ during the "night-time" group. Five patients $(2.3 \%)$ were treated with interventional procedures and two $(0.7 \%)$ received surgical intervention under general anaesthesia. Ureteric necrosis occurred in one "day-time" renal recipient, which was treated with ureteric re-implantation. The incidence of vascular complications within three months post-transplantation was, respectively, $4.5 \%$ for "day-time" and $2.4 \%$ for "night-time" surgery. In four cases $(1.9 \%)$, an early secondary surgical intervention was required for vascular complications. Renal artery stenosis occurred in $0.9 \%$ of all recipients. Renal artery aneurysm and renal vein thrombosis occurred equally at the rate of $0.5 \%$.

Table 3. Postoperative complications with Clavien-Dindo Classification. Results are presented as absolute and relative frequencies. ${ }^{*}$ If more than one occurred per case, according to patient records, the complication with the highest degree was selected (Minor I+II, Major complications IIIa-IVb, Mortality V).

\begin{tabular}{ccccc}
\hline & All $(\boldsymbol{n = 2 1 5 )}$ & $\begin{array}{c}\mathbf{8 : 0 0} \text { a.m.-8:00 p.m. } \\
(\boldsymbol{n}=\mathbf{1 3 2})\end{array}$ & $\begin{array}{c}\mathbf{8 : 0 0} \text { p.m.-8:00 a.m. } \\
(\boldsymbol{n}=\mathbf{8 3})\end{array}$ & $p$-Value \\
\hline Complications (all grades) & $115(46.5 \%)$ & $58(43.9 \%)$ & $42(50.6 \%)$ & 0.340 \\
\hline Grade of complication * & & & & \\
I & $25(11.6 \%)$ & $17(12.9 \%)$ & $8(9.6 \%)$ & 0.470 \\
II & $39(18.1 \%)$ & $24(18.2 \%)$ & $15(18.1 \%)$ & 0.984 \\
IIIa & $15(7.0 \%)$ & $11(8.3 \%)$ & $4(4.8 \%)$ & 0.325 \\
IIIb & $28(13.0 \%)$ & $16(12.0 \%)$ & $12(14.5 \%)$ & 0.620 \\
IVa & $3(1.4 \%)$ & $3(2.3 \%)$ & $0(0 \%)$ & 0.286 \\
IVb & $41.9 \%)$ & $2(1.5 \%)$ & $2(2.4 \%)$ & 0.640 \\
V & $1(0.5 \%)$ & $1(0.8 \%)$ & $0(0 \%)$ & 1.000 \\
\hline
\end{tabular}

Table 4. Incidence of surgical complications. Incidence is expressed as percentages (\%) of total number (n) of patients.

\begin{tabular}{ccccc}
\hline Surgical Complications & All $(\boldsymbol{n}=\mathbf{2 1 5})$ & $\begin{array}{c}\mathbf{8 : 0 0} \text { a.m.-8:00 p.m. } \\
(\boldsymbol{n}=\mathbf{1 3 2})\end{array}$ & $\begin{array}{c}\mathbf{8 : 0 0} \text { p.m.-8:00 a.m. } \\
(\boldsymbol{n}=\mathbf{8 3})\end{array}$ & $p$-Value \\
\hline $\begin{array}{c}\text { Vascular } \\
\text { Renal artery stenosis }\end{array}$ & $2(0.9 \%)$ & $1(0.8 \%)$ & $1(1.2 \%)$ & 1.0 \\
Renal vein thrombosis & $1(0.5 \%)$ & $1(0.8 \%)$ & 0 & 1.0 \\
Iliac artery thrombosis & $1(0.5 \%)$ & $1(0.8 \%)$ & 0 & 1.0 \\
Renal artery aneurysm & $1(0.5 \%)$ & $1(0.8 \%)$ & 0 & 1.0 \\
Renal anastomotic leak & $1(0.5 \%)$ & 0 & $1(1.2 \%)$ & 0.39 \\
Renal pole infarct & $1(0.5 \%)$ & $1(0.8 \%)$ & 0 & 1.0 \\
Coeliac Trunk stenosis & $1(0.5 \%)$ & $1(0.8 \%)$ & 0 & 1.0 \\
\hline
\end{tabular}


Table 4. Cont.

\begin{tabular}{|c|c|c|c|c|}
\hline Surgical Complications & All $(n=215)$ & $\begin{array}{c}\text { 8:00 a.m. }-8: 00 \text { p.m. } \\
(n=132)\end{array}$ & $\begin{array}{c}\text { 8:00 p.m.-8:00 a.m. } \\
(n=83)\end{array}$ & $p$-Value \\
\hline \multicolumn{5}{|l|}{ Haemorrhagic } \\
\hline Haematoma & $31(14 \%)$ & $20(15.2 \%)$ & $11(13.3 \%)$ & 0.70 \\
\hline Haemorrhage & $6(2.8 \%)$ & $3(2.3 \%)$ & $3(3.6 \%)$ & 0.56 \\
\hline \multicolumn{5}{|l|}{ Urological } \\
\hline Urinary leak & $3(1.4 \%)$ & $2(1.5 \%)$ & $1(1.2 \%)$ & 1.0 \\
\hline Urethral necrosis & $1(0.5 \%)$ & $1(0.8 \%)$ & 0 & 1.0 \\
\hline Urethral stent complication & $1(0.5 \%)$ & $1(0.8 \%)$ & 0 & 1.0 \\
\hline Urethral stricture & $2(0.9 \%)$ & $1(0.8 \%)$ & $1(1.2 \%)$ & 1.0 \\
\hline Bladder outflow & & & & \\
\hline $\begin{array}{l}\text { obstruction/Blood clot } \\
\text { retention }\end{array}$ & $4(1.9 \%)$ & $4(3.0 \%)$ & 0 & 0.16 \\
\hline \multicolumn{5}{|l|}{ Wound related } \\
\hline Lymphocele & $23(10.7 \%)$ & $13(9.8 \%)$ & $10(12 \%)$ & 0.53 \\
\hline Seroma & $17(7.9 \%)$ & $9(6.8 \%)$ & $8(9.6 \%)$ & 0.46 \\
\hline Wound dehiscence & $15(7 \%)$ & $9(6.8 \%)$ & $6(7.3 \%)$ & 0.89 \\
\hline Impaired wound healing & $3(1.4 \%)$ & 0 & $3(3.6 \%)$ & 0.06 \\
\hline Wound infection & $3(1.4 \%)$ & $3(2.3 \%)$ & 0 & 0.29 \\
\hline
\end{tabular}

\section{Discussion}

Over the past decade, increased understanding of the effects of shift work and sleep deprivation on neurocognitive functions and physicians health has been established [25]. A single-center study by Rothschild et al. suggested that surgical outcomes were compromised if surgeons had less than six hours of sleep per shift [19]. Traffinder et al. reported that fatigued surgeons made $20 \%$ more errors and took $14 \%$ longer to perform laparoscopic tasks [26]. On the other hand, studies have demonstrated that outcomes of surgical procedures may not be adversely affected by fatigue or disruption of the normal circadian rhythm [16-18]. Five studies with limited numbers of transplants have previously assessed this issue by focusing on the impact of night-time surgery on graft outcome or complications in patients undergoing renal transplantation [21-24]. Only one single-center study, performed by Fechner et al., demonstrated that night-time surgery carries a higher risk of adverse events and poorer outcomes, particularly driven by higher rates of vascular complications [21]. Kienzel et al. reported that, if transplantations were postponed until the next morning, the increase in CIT would decrease the long-term survival [22]. Seow et al. did not observe an adverse effect of night-time surgery on patient outcomes but highlighted surgical clinical expertise to be a crucial factor for surgical complications [23]. Several limitations need to be considered in the interpretation of the contradictory results. Most studies published to date reported great variability in the methodology and outcome measures. In addition, the definition and understanding of sleep deprivation varied widely among previous investigators. Mentioned studies are frequently single-center and reported the results of a small groups of surgeons, which limits the generalizability. In the present study, we did not find any significant impact of night-time kidney transplant surgery on outcomes including three-month and one-year patient or allograft survival, postoperative complications, DGF or AR in the first year. Our analysis revealed a variable incidence of complications among the different time groups and we could not determine any consistent trend. While the incidence of vascular, haemorrhagic and urological complications was greatest in the "day-time" operative group, wound complications occurred more often among recipients of "night-time" transplants without statistical significance. The mean CIT was slightly longer among those who underwent night-time transplant operations compared to the "day-time" cohort. We observed diminished patient survival among "day-time" renal transplant recipients compared to "night-time" allograft recipients, whereas long-term graft survival was unaffected by the time of day. With no significant difference in baseline characteristics, except for the slighter higher distribution of male donors in the "day-time" cohort, the reasons for this observation are still unclear. 
We have controlled for a majority of the clinically meaningful variables available to us in this data set, but it is possible that yet unidentified biologic factors could account for the difference in patient survival between the "night-time" and "day-time" cohorts. With this in mind, there is an urgent need for research in order to clarify the biological consequences of sleep disturbance and fatigue among renal transplant patients. The influence of circadian rhythmicity on physiologic functions related to renal cells, including blood pressure control and homeostasis regulation, is a well-studied phenomenon [27-30]. Evidence suggests that reduced sleep duration and disturbed circadian rhythms may increase sympathetic nervous system stimulation, increase blood pressure, and impair metabolic regulation [31-33]. Thus, misalignment of intrinsic circadian rhythms with environmental time may contribute to poor kidney functioning and renal injury among kidney transplant recipients and donors. Future study is required to clarify this issue. There may be several possible explanations for the lack of 'night-time effect' on outcomes after renal transplantation in this study. Recent studies have demonstrated that there is inter-individual variability in vulnerability to cognitive deficits from sleep loss and the ability to sustain effective neurocognitive performance [34,35], suggesting a reason why there were no differences between the "day-time" and "night-time" cohorts in our study. Van Dongen et al. reported differences in endogenous regulatory processes among individuals, which may affect their tolerance for shift work and cognitive performance during work shifts [36]. Performance adaption across successive shifts has been observed [37,38]. Leff et al. suggested improvement in technical procedural skills across remaining night shifts may be due to ongoing learning or adaption to chronic fatigue [37]. When considering the impact of nocturnal shift work on surgical performance, it is essential to also consider the effects of societal and environmental forces that may contribute to the biological consequences of circadian misalignment. It is known, that there is a detrimental effect of noise inside the operating room on the performance of surgeons and anaesthesiologists [39]. The exposure to excessive operating room noise and distractions during the main day-time business hours may impair cognitive skills. Other factors influencing the performance of a surgeon, such as leadership and communication may be at least as important as technical skills and the number of hours slept [40]. In addition, the use of caffeine and periods of short naps may mitigate the potential risks associated with sleep deprivation [41]. A study of this nature has some limitations, primarily through its retrospective design. The small overall number of patients and individual complications in our cohort might weaken the conclusions of our pilot-study and limits the power to detect differences. To assess severity, we additionally categorised all postoperative complications using the Clavien-Dindo classification system. Although this system has been proven to be reproducible and applicable with minimal interobserver variability, it has some limitations [42]. Data regarding a surgeon's subjective perception of fatigue, resting time and quantification of sleep deprivation were not available and could not be included in the analysis. It is further possible, that transplant surgeons perform day-time procedures beginning at 8 am after being 'on-call' overnight. With that in mind, one may argue whether the classification based on time group selections assumes that day-time surgeons are well rested, and perform better than night-time surgeons regardless of their overall workload. We cannot lose sight of other potential variables such as the effect of procurement-related organ lesions on renal transplant outcome. Data concerning surgeons' fitness before procurement were not available. Further investigation is needed aiming to record errors during organ procurement related to surgeons' fatigue.

\section{Concluding Remarks and Future Directions}

To date, there are very few reports on the effect of night-time surgery on renal transplant outcomes. We, therefore, believe that the initial results from this pilot-study are a welcome addition to the urological literature and provide encouragement for further analysis. We concluded that night- time kidney surgery does not carry a higher risk of adverse events and poorer outcome among patients undergoing renal transplantation. Consequently, kidney transplantation should be immediately performed regardless of the time of the day, with the known adverse effects of prolonged CIT. However, in order to fully assess the effects of sleep deprivation and circadian rhythm disturbance on surgical 
performance in kidney transplantation, prospective research involving larger cohorts is needed. Therefore, among other things, a transparent evidence-based assessment of the level of fatigue, shift intensity and sleep quality in medicine, especially in the field of surgery, is required. Moreover, systems-based interventions, as well as individual coping strategies and experiences that mitigate the effects of fatigue and disruption of the circadian rhythms, should be taken into consideration. In addition, there is a need for future research focusing on the impact of sleep displacement and circadian misalignment on renal functioning among recipients and donors in the field of kidney transplantation.

Author Contributions: F.F., K.B. and L.L. designed the study; N.S. analyzed the data and wrote the manuscript; A.B., R.P., T.S. and N.B. drafted and revised the paper; all authors approved the final version of the manuscript.

Acknowledgments: We acknowledge support from the German Research Foundation (DFG) and the Open Access Publication Fund of Charité-Universitätsmedizin Berlin.

Conflicts of Interest: The authors have no conflict of interest to disclose.

\section{References}

1. Hariharan, S.; Johnson, C.P.; Bresnahan, B.A.; Taranto, S.E.; McIntosh, M.J.; Stablein, D. Improved graft survival after renal transplantation in the United States, 1988 to 1996. N. Engl. J. Med. 2000, 342, 605-612. [CrossRef] [PubMed]

2. Halloran, P.F. Immunosuppressive drugs for kidney transplantation. N. Engl. J. Med. 2004, 351, $2715-2729$. [CrossRef] [PubMed]

3. Brockschmidt, C.; Huber, N.; Paschke, S.; Hartmann, B.; Henne-Bruns, D.; Wittau, M. Minimal access kidney transplant: A novel technique to reduce surgical tissue trauma. Exp. Clin. Transplant. 2012, 10, 319-324. [CrossRef] [PubMed]

4. Bessede, T.; Droupy, S.; Hammoudi, Y.; Bedretdinova, D.; Durrbach, A.; Charpentier, B.; Benoit, G. Surgical prevention and management of vascular complications of kidney transplantation. Transpl. Int. 2012, 25, 994-1001. [CrossRef] [PubMed]

5. Osman, Y.; Shokeir, A.; Ali-el-Dein, B.; Tantawy, M.; Wafa, E.W.; el-Dein, A.B.; Ghoneim, M.A. Vascular complications after live donor renal transplantation: Study of risk factors and effects on graft and patient survival. J. Urol. 2003, 169, 859-862. [CrossRef] [PubMed]

6. Phelan, P.J.; O’Kelly, P.; Tarazi, M.; Tarazi, N.; Salehmohamed, M.R.; Little, D.M.; Magee, C.; Conlon, P.J. Renal allograft loss in the first post-operative month: Causes and consequences. Clin. Transplant. 2012, 26, 544-549. [CrossRef]

7. Humar, A.; Matas, A.J. Surgical complications after kidney transplantation. Semin. Dial. 2005, 18, 505-510. [CrossRef]

8. Debout, A.; Foucher, Y.; Trébern-Launay, K.; Legendre, C.; Kreis, H.; Mourad, G.; Garrigue, V.; Morelon, E.; Buron, F.; Rostaing, L.; et al. Each additional hour of cold ischemia time significantly increases the risk of graft failure and mortality following renal transplantation. Kidney Int. 2015, 87, 343-349. [CrossRef]

9. Olson, E.J.; Drage, L.A.; Auger, R.R. Sleep deprivation, physician performance, and patient safety. Chest 2009, 136, 1389-1396. [CrossRef]

10. Lockley, S.W.; Barger, L.K.; Ayas, N.T.; Rothschild, J.M.; Czeisler, C.A.; Landrigan, C.P.; Harvard Work Hours, Health and Safety Group. Effects of health care provider work hours and sleep deprivation on safety and performance. Jt. Comm. J. Qual. Patient Saf. 2007, 33 (Suppl. 11), 7-18. [CrossRef]

11. Eastridge, B.J.; Hamilton, E.C.; O’Keefe, G.E.; Rege, R.V.; Valentine, R.J.; Jones, D.J.; Tesfay, S.; Thal, E.R. Effect of sleep deprivation on the performance of simulated laparoscopic surgical skill. Am. J. Surg. 2003, 186, 169-174. [CrossRef]

12. Gerdes, J.; Kahol, K.; Smith, M.; Leyba, M.J.; Ferrara, J.J. Jack Barney award: The effect of fatigue on cognitive and psychomotor skills of trauma residents and attending surgeons. Am. J. Surg. 2008, 196, 813-819, discussion 819-820. [CrossRef]

13. Peskun, C.; Walmsley, D.; Waddell, J.; Schemitsch, E. Effect of surgeon fatigue on hip and knee arthroplasty. Can. J. Surg. 2012, 55, 81-86. [CrossRef] 
14. Kelz, R.R.; Freeman, K.M.; Hosokawa, P.W.; Asch, D.A.; Spitz, F.R.; Moskowitz, M.; Henderson, W.G.; Mitchell, M.E.; Itani, K.M. Time of day is associated with postoperative morbidity: An analysis of the national surgical quality improvement program data. Ann. Surg. 2008, 247, 544-552. [CrossRef]

15. Egol, K.A.; Tolisano, A.M.; Spratt, K.F.; Koval, K.J. Mortality rates following trauma: The difference is night and day. J. Emerg. Trauma Shock 2011, 4, 178-183.

16. Schieman, C.; MacLean, A.R.; Buie, W.D.; Rudmik, L.R.; Ghali, W.A.; Dixon, E. Does surgeon fatigue influence outcomes after anterior resection for rectal cancer? Am. J. Surg. 2008, 195, 684-687, discussion 687-688. [CrossRef]

17. Yaghoubian, A.; Kaji, A.H.; Ishaque, B.; Park, J.; Rosing, D.K.; Lee, S.; Stabile, B.E.; de Virgilio, C. Acute care surgery performed by sleep deprived residents: Are outcomes affected? J. Surg. Res. 2010, 163, 192-196. [CrossRef]

18. Ellman, P.I.; Kron, I.L.; Alvis, J.S.; Tache-Leon, C.; Maxey, T.S.; Reece, T.B.; Peeler, B.B.; Kern, J.A.; Tribble, C.G. Acute sleep deprivation in the thoracic surgical resident does not affect operative outcomes. Ann. Thorac. Surg. 2005, 80, 60-64, discussion 64-65. [CrossRef]

19. Rothschild, J.M.; Keohane, C.A.; Rogers, S.; Gardner, R.; Lipsitz, S.R.; Salzberg, C.A.; Yu, T.; Yoon, C.S.; Williams, D.H.; Wien, M.F.; et al. Risks of complications by attending physicians after performing nighttime procedures. JAMA 2009, 302, 1565-1572. [CrossRef]

20. Lonze, B.E.; Parsikia, A.; Feyssa, E.L.; Khanmoradi, K.; Araya, V.R.; Zaki, R.F.; Segev, D.L.; Ortiz, J.A. Operative start times and complications after liver transplantation. Am. J. Transplant. 2010, 10, 1842-1849. [CrossRef]

21. Fechner, G.; Pezold, C.; Hauser, S.; Gerhardt, T.; Muller, S.C. Kidney's nightshift, kidney's nightmare? Comparison of daylight and nighttime kidney transplantation: Impact on complications and graft survival. Transplant. Proc. 2008, 40, 1341-1344. [CrossRef]

22. Kienzl-Wagner, K.; Schneiderbauer, S.; Bosmuller, C.; Schneeberger, S.; Pratschke, J.; Ollinger, R. Nighttime procedures are not associated with adverse outcomes in kidney transplantation. Transpl. Int. 2013, 26, 879-885. [CrossRef]

23. Seow, Y.Y.; Alkari, B.; Dyer, P.; Riad, H. Cold ischemia time, surgeon, time of day, and surgical complications. Transplantation 2004, 77, 1386-1389. [CrossRef]

24. Brunschot, D.M.; Hoitsma, A.J.; van der Jagt, M.F.; d'Ancona, F.C.; Donders, R.A.; van Laarhoven, C.J.; Hilbrands, L.B.; Warle, M.C. Nighttime kidney transplantation is associated with less pure technical graft failure. World J. Urol. 2016, 34, 955-961. [CrossRef]

25. Van Dongen, H.P.; Maislin, G.; Mullington, J.M.; Dinges, D.F. The cumulative cost of additional wakefulness: Dose-response effects on neurobehavioral functions and sleep physiology from chronic sleep restriction and total sleep deprivation. Sleep 2003, 26, 117-126. [CrossRef]

26. Taffinder, N.J.; McManus, I.C.; Gul, Y.; Russell, R.C.; Darzi, A. Effect of sleep deprivation on surgeons' dexterity on laparoscopy simulator. Lancet 1998, 352, 1191. [CrossRef]

27. Zuber, A.M.; Centeno, G.; Pradervand, S.; Nikolaeva, S.; Maquelin, L.; Cardinaux, L.; Bonny, O.; Firsov, D. Molecular clock is involved in predictive circadian adjustment of renal function. Proc. Natl. Acad. Sci. USA 2009, 106, 16523-16528. [CrossRef]

28. Myung, J.; Wu, M.Y.; Lee, C.Y.; Rahim, A.R.; Truong, V.H.; Wu, D.; Piggins, H.D.; Wu, M.S. The Kidney Clock Contributes to Timekeeping by the Master Circadian Clock. Int. J. Mol. Sci. 2019, 20, 2765. [CrossRef]

29. Tokonami, N.; Mordasini, D.; Pradervand, S.; Centeno, G.; Jouffe, C.; Maillard, M.; Bonny, O.; Gachon, F.; Gomez, R.A.; Sequeira-Lopez, M.L.; et al. Local renal circadian clocks control fluid-electrolyte homeostasis and BP. J. Am. Soc. Nephrol. 2014, 25, 1430-1439. [CrossRef]

30. Gumz, M.L. Tick tock: Time to recognize the kidney clock. J. Am. Soc. Nephrol. 2014, 25, 1369-1371. [CrossRef]

31. Spiegel, K.; Leproult, R.; Van Cauter, E. Impact of sleep debt on metabolic and endocrine function. Lancet 1999, 354, 1435-1439. [CrossRef]

32. Sayk, F.; Teckentrup, C.; Becker, C.; Heutling, D.; Wellhöner, P.; Lehnert, H.; Dodt, C. Effects of selective slow-wave sleep deprivation on nocturnal blood pressure dipping and daytime blood pressure regulation. Am. J. Physiol. Regul. Integr. Comp. Physiol. 2010, 298, R191-R197. [CrossRef]

33. Spiegel, K.; Tasali, E.; Leproult, R.; Van Cauter, E. Effects of poor and short sleep on glucose metabolism and obesity risk. Nat. Rev. Endocrinol. 2009, 5, 253-261. [CrossRef] 
34. Van Dongen, H.P.; Bender, A.M.; Dinges, D.F. Systematic individual differences in sleep homeostatic and circadian rhythm contributions to neurobehavioral impairment during sleep deprivation. Accid. Anal. Prev. 2012, 45, 11-16. [CrossRef]

35. Chee, M.W.; Tan, J.C. Lapsing when sleep deprived: Neural activation characteristics of resistant and vulnerable individuals. Neuroimage 2010, 51, 835-843. [CrossRef]

36. Van Dongen, H.P. Shift work and inter-individual differences in sleep and sleepiness. Chronobiol. Int. 2006, 23, 1139-1147. [CrossRef]

37. Leff, D.R.; Aggarwal, R.; Rana, M.; Nakhjavani, B.; Purkayastha, S.; Khullar, V.; Darzi, A.W. Laparoscopic skills suffer on the first shift of sequential night shifts: Program directors beware and residents prepare. Ann. Surg. 2008, 247, 530-539. [CrossRef]

38. Lamond, N.; Dorrian, J.; Roach, G.D.; McCulloch, K.; Holmes, A.L.; Burgess, H.J.; Fletcher, A.; Dawson, D. The impact of a week of simulated night work on sleep, circadian phase, and performance. Occup. Environ. Med. 2003, 60, e13. [CrossRef]

39. Katz, J.D. Noise in the operating room. Anesthesiology 2014, 121, 894-898. [CrossRef]

40. Moorthy, K.; Munz, Y.; Forrest, D.; Pandey, V.; Undre, S.; Vincent, C.; Darzi, A. Surgical crisis management skills training and assessment: A simulation[corrected]-based approach to enhancing operating room performance. Ann. Surg. 2006, 244, 139-147. [CrossRef]

41. Aggarwal, R.; Mishra, A.; Crochet, P.; Sirimanna, P.; Darzi, A. Effect of caffeine and taurine on simulated laparoscopy performed following sleep deprivation. Br. J. Surg. 2011, 98, 1666-1672. [CrossRef] [PubMed]

42. Yoon, P.D.; Chalasani, V.; Woo, H.H. Use of Clavien-Dindo classification in reporting and grading complications after urological surgical procedures: Analysis of 2010 to 2012. J. Urol. 2013, 190, 1271-1274. [CrossRef]

(C) 2019 by the authors. Licensee MDPI, Basel, Switzerland. This article is an open access article distributed under the terms and conditions of the Creative Commons Attribution (CC BY) license (http://creativecommons.org/licenses/by/4.0/). 